PAPER

\title{
Long term effect (more than five years) of intrathecal baclofen on impairment, disability, and quality of life in patients with severe spasticity of spinal origin
}

\author{
A Zahavi, J H B Geertzen, B Middel, M Staal, J S Rietman
}

J Neurol Neurosurg Psychiatry 2004;75:1553-1557. doi: 10.1136/jnnp.2003.014282

See end of article for authors' affiliations

.....................

Correspondence to: DrJ H B Geertzen, Department of Rehabilitation, University Groningen Hospital Hanzeplein 1, 9700 RB Groningen, Netherlands; j.h.b.geertzen@rev.azg.nl

Received 11 March 2003 Revised 1 February 2004 Accepted

13 February 2004

\begin{abstract}
Objectives: To evaluate long term change in impairment, disability, and health related functional status in patients with severe spasticity who received intrathecal baclofen.

Methods: A long term (more than five years) observational longitudinal follow up study assessing 21 patients who received intrathecal baclofen given by programmable pump. Patients had chronic disabling spasticity which did not respond to oral antispasmolytic agents. Clinical efficacy was assessed by the Ashworth scale and spasm score; disability by the expanded disability status scale (EDSS), ambulation index (AI), and incapacity status scale (ISS); and health related quality of life by the sickness impact profile (SIP) and the Hopkins symptom checklist (HSCL).

Results: Compared with pretreatment values, there was a significant improvement in clinical efficacy (Ashworth scale and spasm score, $\mathrm{p}<0.05$ ) but a small but significant worsening of disability (EDSS, Al, and ISS, $\mathrm{p}<0.05$ ). Comparing pretreatment with 26 weeks after pump implantation, a worsening was observed in disability (EDSS and ISS, $\mathrm{p}<0.05$ ) and perceived health status (SIP, psychosocial dimension, $\mathrm{p}<0.05)$.

Conclusions: Long term administration of intrathecal baclofen delivered by an implanted programmable pump resulted in improved clinical efficacy but not in improvement in disability or perceived health status.
\end{abstract}

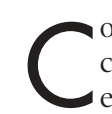

ontinuous intrathecal baclofen infusion using a subcutaneously implanted programmable pump has been employed in the treatment of severe spasticity since its introduction by Penn and Kroin in $1984 .^{1}$ Since then, there have been several clinical reports on the use of continuous intrathecal baclofen to reduce spasticity, indicating that it is very effective. Baclofen, an agonist of the inhibitory neurotransmitter $\gamma$-aminobutyric acid (GABA), is an inhibitor of the segmental polysynaptic spinal reflex pathways and is often used in the treatment of spasticity. Intrathecal administration of baclofen acts directly at the receptor sites in the spinal cord, resulting in greater therapeutic efficacy with smaller drug doses and thus less systemic toxicity than with oral preparations. ${ }^{2}$ Oral antispasmolytics are often poorly tolerated at the high doses needed to achieve a reduction in spasticity. ${ }^{3}$

Intrathecal baclofen not only results in a decrease in spasticity but may also lead to an improvement in disability and perceived health status as determined by quality of life and health related measures. ${ }^{4-6}$ However, little attention has been paid to evaluating the effects on quality of life in patients receiving intrathecal baclofen, and few studies have specifically addressed the question of functional improvement (impairment, disability, and perceived health status) with the long term use of intrathecal baclofen. ${ }^{45}$ Various studies have reviewed the long term effects of intrathecal baclofen in patients with spinal spasticity, but in most of these the patients were followed up for relatively short periods (rarely extending beyond two years). ${ }^{4-17}$ These studies have concentrated mainly on measuring neurological (Ashworth scale and spasm score), neurophysiological (electromyographic), urological (bladder function), and other measurements of impairment. Measurements relating to disability and quality of life have been applied sparsely if at all. To our knowledge, only two studies have addressed the issues of quality of life in patients receiving intrathecal baclofen but few patients were followed up for longer than two years. ${ }^{45}$ The functional independence measure (FIM), ${ }^{4}$ quality of life index (QLI), ${ }^{5}$ and sickness impact profile (SIP) ${ }^{5}$ were used. However, mean follow up was 37.4 months in one study ${ }^{4}$ and only 12 months in the other. ${ }^{5}$ There was a significant increase in FIM and SIP scores.

In the present study we aimed to evaluate long term change in impairment, disability, and health related functional status in patients treated with intrathecal baclofen for severe spasticity resulting from spinal pathology.

\section{METHODS}

\section{Selection of patients}

In a previous prospective multicentre trial, patients with intractable spasticity caused by spinal pathology were treated with intrathecal baclofen and followed up to one year. ${ }^{6}$ Patients with severe spasticity associated with multiple sclerosis or spinal cord injury who had been referred by their general practitioners or specialists were recruited from the neurology, rehabilitation, and neurosurgery departments of nine Dutch hospitals. Patients were included in the study when they met the following criteria:

- age 18 years or over, with chronic disabling spasticity of spinal origin inhibiting personal care, sitting, lying, and transfers, accompanied by pain and stiffness, or disturbed sleep;

- insufficient response to treatment with maximal doses of oral baclofen, dantrolene, and tizanidine;

- sufficient understanding of the consequences of the treatment.

Abbreviations: Al, ambulation index; EDSS, expanded disability status scale; ES, effect size; FIM, functional independence measure; HSCL, Hopkins symptom checklist; ISS, incapacity status scale; QLI, quality of life index; SIP, sickness impact profile 
Patients who were pregnant, had neurological symptoms of supraspinal origin, or were allergic to baclofen were excluded. ${ }^{6}$

During a four year period extending from 1991 to 1995, a programmable pump for injecting intrathecal baclofen was implanted in 38 patients. ${ }^{6}$ This group was the subject of the present study.

\section{Study design}

A long term observational longitudinal follow up study was undertaken to compare the effects of intrathecal baclofen (given for more than five years) with status before pump implantation and 26 weeks after starting intrathecal treatment. The same clinical assessments and questionnaires as used in the original study were given during the follow up. ${ }^{6}$ As more patients in the first study were followed up for 26 weeks than for one year, we decided to compare current measurements with those taken at the start of the study and at 26 weeks of follow up, as there were likely to be more data available.

\section{Measures \\ Assessment of impairment (clinical efficacy): Ashworth scale and spasm score}

The Ashworth scale and spasm score are clinical assessment scales for spasticity. ${ }^{18}$ To calculate the Ashworth score the grades for hip flexion/extension, hip abduction and adduction, knee flexion/extension, and ankle dorsal flexion/ extension on each side were summed and divided by eight. The modified Ashworth scale has five grades. ${ }^{18}$ The spasm score evaluates the frequency of spasms with scores of 0 (no spasm), 1 (mild spasms induced by stimulation), 2 (infrequent spasms occurring less than once an hour), 3 (spasms occurring more than once an hour), and 4 (spasms occurring more than 10 time an hour). Only the spasm scores of the lower extremities were measured. We also assessed the range of motion of the lower extremities and whether contractures were present.

Assessment of disability: expanded disability status scale, ambulation index, and incapacity status scale The expanded disability status scale (EDSS) measures the level of ambulation and the presence of somatic complaints on a scale of zero to $10.0(0=$ no complaints or impairment; $10.0=$ death $).{ }^{19}$ The ambulation index $(\mathrm{AI})$ gives an impression of walking ability on a scale of zero to 9, with zero being fully ambulatory and 9 being wholly restricted to a wheelchair and unable to achieve independent transfer. There is a partial overlap with the EDSS. The incapacity status scale (ISS) measures activities of daily living. This scale consists of 16 items concerning daily activities such as mobility, bowel and bladder function, and dressing. Each item is scored from zero to $4 \quad(0=$ no impairment; $4=$ patient is unable to perform task or needing maximal assistance). ${ }^{20}$

\section{Assessment of perceived health status: sickness} impact profile and Hopkins symptom check list The sickness impact profile (SIP) is a behaviour based self report measure that is used to quantify sickness related dysfunction. ${ }^{21}$ Patients are asked to complete a standardised questionnaire consisting of 136 items aggregated into 12 domains of daily functioning. The Hopkins symptom check list (HSCL) was translated and validated for the Dutch situation by Luteyn et al. ${ }^{22}$ It consists of 57 items with two subscales (mental health and physical health) and an overall scale, and ranges from zero to $171(0=$ no complaints at all).

\section{Dosages, complications, and patient survey}

The dosages of intrathecal baclofen were obtained by examination of the patient's clinical records. The maximum dosages over the period of treatment and the current dose at the time of the assessments were obtained. Differences in maximum and mean dosages between subjects suffering from a progressive disease such as multiple sclerosis and a non-progressive disease such as spinal cord injury were also assessed.

Complications were registered by evaluating the patient's records and by questioning individual subjects. Complications were categorised as pharmacological (a direct result of the baclofen) and technical (from malfunction of the pump system). Complications from the surgical procedure of implanting the pump (wounds, meningitis, cerebrospinal fluid leakage) were also noted.

The duration of treatment (in months) was recorded, beginning from the start of intrathecal administration and ending at the final evaluation.

We constructed a non-standardised questionnaire subjectively evaluating the patient's response to treatment with intrathecal baclofen. The aim of this questionnaire was to determine the patient's overall satisfaction with the treatment, independent of the information obtained from the various clinical and health related measurements.

\section{Statistical methods}

The changes in clinical efficacy, disability, and health related quality of life between 26 weeks and the final assessment, and between baseline and the final assessment were analysed using the Wilcoxon matched pairs signed ranks test. Subgroup analysis (progressive versus non-progressive disease) was carried out to determine whether there were differences in dosages and measurements of impairments, disability, and perceived health status. Effect sizes (ES) were calculated according to Cohen. ${ }^{23}$ Effect sizes are often used to give meaning to differences between groups or between baseline and outcome in terms "trivial" (ES <0.20), "small" (ES $\geqslant 0.20$ but $<0.50)$, "moderate" (ES $\geqslant 0.50$ but $<0.80$ ), or "large" (ES $\geqslant 0.80)$. Data were analysed using SPSS version 10.0 statistical software. Probability $(p)$ values of $<0.05$ were considered significant.

\section{RESULTS}

All pumps were implanted between 1991 and 1995, thus guaranteeing a follow up period of at least five years. Using the same clinical and health related measures as in the previous study ${ }^{6}$ allowed the most objective and accurate comparison of health related outcomes over an extended period of time in patients receiving intrathecal baclofen. Of the 38 patients originally included in the study 21 were available for follow up. Of the remainder, four were eventually excluded (in one patient the pump was removed because of an infection; in three the administration of intrathecal baclofen was discontinued for various reasons); nine died from complications of the underlying spinal disease or other medical illnesses not related to the spinal disorder; two refused to participate in the study; and two could not be located. The results of the evaluations of clinical efficacy and health related quality of life in the 21 patients who were finally included were compared with those obtained at the start of the study and at the 26 week assessment.

Table 1 gives the overall characteristics of the patient population and the length of treatment. The mean (SD) age of the sample was 54.6 (12.5) years (range 31 to 76 ); $43 \%$ were women, and 53\% had progressive disease (multiple sclerosis in all cases). Among the patients with a nonprogressive disease, there were six cases of spinal cord injury. 
Table 1 Patient characteristics and length of treatment $(n=21)$

\begin{tabular}{llll}
\hline & $\begin{array}{l}\text { Total } \\
(\mathbf{n}=\mathbf{2 1})\end{array}$ & $\begin{array}{l}\text { Progressive* } \\
(\mathbf{n = 1 1 )}\end{array}$ & $\begin{array}{l}\text { Non- } \\
\text { progressivet } \\
(\mathbf{n}=10)\end{array}$ \\
\hline $\begin{array}{l}\text { Age (years) (mean (SD)) } \\
\text { Length of treatment } \\
\text { (months) }\end{array}$ & $54.6(12.5)$ & $57.2(9.2)$ & $51.8(15.4)$ \\
$\quad \begin{array}{lll}\text { Mean (SD) } \\
\text { Range }\end{array}$ & $84.9(13.1)$ & $90.3(11.1)$ & $78.9(12.9)$ \\
$\begin{array}{l}\text { Sex (n) } \\
\text { Male }\end{array}$ & 66 to 108 & 80 to 108 & 66 to 101 \\
Female & 12 & 3 & 9 \\
\hline
\end{tabular}

*Progressive: multiple sclerosis (11).

†Non-progressive: spinal cord injury (6), adrenalopathy (1), anterior spinal syndrome (1), radiation myelopathy (1), spinal angioma (1).

The mean duration of treatment was 84.9 months (range 66 to 108$)$.

Table 2 summarises the results of the assessments of impairment (Ashworth scale and spasm score), disability (EDSS, AI, and ISS), and health outcome measures (SIP and HSCL) at baseline, 26 weeks after baseline, and at the final evaluation. At the final evaluation, there was significant improvement in the level of impairment (Ashworth scale and spasm score, $\mathrm{p}<0.05$ ) and a small but significant worsening in the level of disability (EDSS, AI, and ISS, p<0.05) compared with baseline values. There was also a significant worsening in the level of disability (EDSS and ISS, $\mathrm{p}<0.05$ ) and in one dimension (psychosocial) of perceived health status (SIP, $\mathrm{p}<0.05)$ compared with the assessments at 26 weeks of treatment. There were no significant differences between patients suffering from a progressive disorder and those with a non-progressive disorder at baseline, 26 weeks, or final assessment in any measurement of impairment, disability, or perceived health status (data not presented).

Table 3 summarises the dosages (current dosage and maximum administered dosage within the treatment period) of baclofen $(\mu \mathrm{g} /$ day $)$. The patient population is divided into those with a progressive spinal disease and those with a nonprogressive disorder. There was no significant difference in mean or maximum dosage between patients suffering from a progressive disease and those with a non-progressive disease. In some patients a slight increase in dosage during follow up was recorded. However, there were some fluctuations in dosage owing to changes in spasticity or other complications.

Table 4 summarises the complications occurring during treatment with intrathecal baclofen. The complications are categorised into those caused by the pharmacological effects of baclofen and those caused by technical problems with the pump. The total number of complications, both pharmacological and technical, was recorded and is independent of the number of patients experiencing these complications.

All patients except two were satisfied with the overall treatment and indicated that they would recommend the treatment to other patients with spasticity. Notwithstanding the time and effort required and the complications inherent in this type of treatment, they would willingly undergo it again if necessary. The most prominent improvements reported by the patients were increased ease of transfer, better seating posture, ease of care in activities of daily living (passive), and decrease in pain. However, only a few patients said that they could carry out more activities than before. Of the two patients who were not satisfied with the treatment, one had experienced five recent episodes of catheter dysfunction, and one acquired an allergy which, after extensive dermatological evaluation, was thought most likely to be caused by baclofen sensitivity and resulted in an irritating itch and skin manifestations.

\section{DISCUSSION}

There was significant improvement in the clinical efficacy scales (Ashworth scale and spasm score) after long term follow up in these patients with intrathecal baclofen treatment compared with baseline scores. As expected, there was no significant improvement between the final assessment and the 26 weeks assessment. When evaluating disabilities there was a small but significant worsening (except for the ambulation index) at the final assessment

Table 2 Evaluation of impairment, disability, and health related functional status at baseline, 26 weeks, and final assessment

\begin{tabular}{|c|c|c|c|c|c|c|c|c|c|}
\hline \multirow[b]{2}{*}{ Instrument (sub)scale } & \multirow[b]{2}{*}{ Baseline score } & \multirow[b]{2}{*}{$\begin{array}{l}\text { Score after } \\
26 \text { weeks }\end{array}$} & \multirow[b]{2}{*}{ Final assessment† } & \multicolumn{3}{|c|}{ Final $v$ baselineł score } & \multicolumn{3}{|c|}{$\begin{array}{l}\text { Final } v 26 \text { weeks after treatment } \\
\text { score }\end{array}$} \\
\hline & & & & $z$ Value & $\mathrm{p}$ Value & $\begin{array}{l}\text { Effect } \\
\text { size§ }\end{array}$ & $z$ Value & $\mathrm{p}$ Value & Effect size \\
\hline Ashworth scale & $2.82(0.86)$ & $1.16(0.99)$ & $0.91(0.90)$ & -3.74 & $0.00^{*}$ & 2.46 & -0.90 & 0.95 & \\
\hline Spasm score & $1.79(0.56)$ & $0.94(0.53)$ & $0.67(1.10)$ & -3.12 & $0.001^{*}$ & 1.52 & -1.19 & 0.26 & \\
\hline Expanded disability status scale & $7.71(0.81)$ & $7.59(0.86)$ & $7.88(0.91)$ & -2.35 & $0.023^{*}$ & 0.88 & -2.26 & $0.031^{*}$ & 1.26 \\
\hline Ambulation index & $7.74(1.48)$ & $7.64(1.75)$ & $8.05(1.56)$ & -2.32 & $0.027^{*}$ & 0.80 & -1.83 & 0.125 & \\
\hline \multicolumn{10}{|l|}{ Incapacity status scale } \\
\hline Overall score & $25.74(8.43)$ & $25.27(10.38)$ & $28.76(10.36)$ & -2.48 & $0.011^{*}$ & 0.50 & -2.36 & $0.016^{*}$ & 0.53 \\
\hline \multicolumn{10}{|l|}{ Sickness impact profile categories } \\
\hline Sleep and rest & $24.21(17.86)$ & 19.32 (15.89) & $29.62(19.56)$ & -0.74 & 0.48 & & -1.85 & 0.07 & \\
\hline Recreation and pastimes & $33.62(24.02)$ & $29.36(24.17)$ & $43.66(29.04)$ & -0.92 & 0.37 & & -1.60 & 0.12 & \\
\hline Mobility & $28.99(21.76)$ & $26.97(11.63)$ & $31.42(23.05)$ & -0.81 & 0.44 & & -0.35 & 0.76 & \\
\hline Body care and movement & $44.13(16.65)$ & $37.08(16.40)$ & $43.20(17.17)$ & -0.39 & 0.71 & & -0.40 & 0.71 & \\
\hline Physical dimension & $36.94(12.51)$ & 34.04 (11.62) & 34.46 (13.18) & -0.56 & 0.60 & & -0.17 & 0.89 & \\
\hline Psychosocial dimension & $13.50(10.39)$ & $10.88(10.90)$ & $19.00(16.91)$ & -1.38 & 0.18 & & -2.58 & $0.01^{*}$ & 1.08 \\
\hline \multicolumn{10}{|l|}{ Hopkins symptom check list } \\
\hline Physical health & $4.75(3.11)$ & $3.76(3.40)$ & $3.71(2.81)$ & -1.380 & 0.18 & & -0.71 & 0.50 & \\
\hline Mental health & 7.55 (5.29) & $5.71(6.03)$ & $7.43(6.27)$ & -0.04 & 0.98 & & -0.04 & 0.12 & \\
\hline Total score & $29.70(15.42)$ & $24.00(18.51)$ & $26.70(16.96)$ & -0.48 & 0.64 & & -1.48 & 0.15 & \\
\hline \multicolumn{10}{|c|}{$\begin{array}{l}\text { Scores are mean (SD). } \\
\text { *p values }<0.05 \text { are considered significant. } \\
\text { tFinal assessment at a mean follow up period of } 84.9 \text { months. } \\
\text { †Baseline }=\text { pretreatment. } \\
\text { §Only effect sizes for significant outcomes were determined. }\end{array}$} \\
\hline
\end{tabular}


Table 3 Dosages of baclofen used ( $\mu \mathrm{g} /$ day)

\begin{tabular}{|c|c|c|c|c|}
\hline & Total & Progressive & Non-progressive & $\begin{array}{l}\text { Progressive } v \text { non- } \\
\text { progressive ( } p \text { value) }\end{array}$ \\
\hline $\begin{array}{l}\text { Mean (current } \\
\text { evaluation) }\end{array}$ & $290.63(272.51)$ & $366.32(359.76)$ & $207.37(80.69)$ & 0.181 \\
\hline $\begin{array}{l}\text { Maximum (over } \\
\text { treatment period) }\end{array}$ & 481.91 (434.83) & $656.37(533.16)$ & $289.99(161.83)$ & 0.051 \\
\hline
\end{tabular}

compared with the baseline scores and the 26 week assessment. For measurement of perceived health status there was a significant increase only in the SIP psychosocial dimension when comparing the final situation with the 26 weeks assessment. However, all the patients except two were satisfied with the overall treatment.

The Ashworth and spasm scores of the lower extremities were assessed, as most patients, including those with multiple sclerosis, suffered from spasticity and spasms only in the lower extremities. It should be noted that spasm, spasticity, and baclofen dosage may not be related only to progression or temporary exacerbation of the disease, as occurs in relapse in multiple sclerosis. Other factors affecting spasticity and spasms such as pump and catheter dysfunction, urinary tract infections, wounds, pressure sores, and other medical conditions were also evaluated, as these could influence the measurements as well as the dose of intrathecal baclofen used. We also examined whether the patients were receiving other treatments such as physical therapy, orthoses, and drugs influencing spasticity or spasms, and whether contractures were present. None of these factors was considered to have a significant effect on treatment outcomes. As dosages would be adjusted continuously during treatment to minimise spasm and spasticity, no differences were found when comparing the present situation with that at 26 weeks after pump implantation.

When interpreting the assessment of disability, the results obtained do not necessarily translate into a significant clinical deterioration. When comparing the mean values of the EDSS and AI, the difference was less than 0.5 point $(0.17$ and 0.29 , respectively). No large improvement in disability

Table 4 Complications occurring during treatment with intrathecal baclofen

\begin{tabular}{lcc}
\hline & $\begin{array}{l}\text { Total } \\
\text { events }(\mathbf{n})\end{array}$ & $\begin{array}{c}\text { Per cent of } \\
\text { total events }\end{array}$ \\
\hline Pharmacological & 70 & 60 \\
Muscle weakness & 16 & 14 \\
Hypotension & 3 & 3 \\
Somnolescence/tiredness & 13 & 11 \\
Dizziness & 4 & 3 \\
Respiratory difficulty & 6 & 5 \\
Dysarthria & 6 & 5 \\
Psychiatric (hallucinations, derealisation) & 5 & 4 \\
Epileptic insults & 3 & 3 \\
Other & 14 & 12 \\
& & \\
Technical/surgical & 47 & 40 \\
Pump related & 4 & 3 \\
Catheter related & 27 & 23 \\
Surgery related & 14 & 12 \\
Other & 2 & 2 \\
\hline
\end{tabular}

Only complications occurring more than once are included. Other less frequent complications included: headache, visual disturbances, skin problems, fainting spells, urinary incontinence, feeling of heaviness, nausea, vomiting, bradycardia, autonomic dysregulation, meningitis, and bacteraemia was expected, as most of the patients were non-ambulant at the start of the treatment.

The progressive nature of disease in more than half the patients was also likely to affect the results of perceived health status. The first study did show a significant improvement in the physical dimensions but not in the psychosocial dimensions. ${ }^{6}$ More than half the patients were over 50 years old, which may also explain why no change is seen in the physical aspects of perceived health status. It should also be noted that the psychosocial dimensions are not only related to achieving adequate control of spasticity and spasms, but may also be related to other factors and circumstances. For example, complications relating to the baclofen pump could have influenced the results of the psychosocial aspects of perceived health status.

All patients had a reasonably stable dosage in the weeks preceding the assessment. The mean final dosages were similar to those in other studies assessing the effects of intrathecal baclofen on spasticity of spinal origin. ${ }^{4}{ }^{10}$ 14-16 24-26 Three studies ${ }^{426}$ evaluated whether there was a significant difference between doses in patients with a progressive compared with a non-progressive disorder. Two showed a statistically significant difference. In the present study we found no significant difference in dosages (mean and maximum) in patients with a progressive compared with a non-progressive disorder, although there seemed to be a trend towards higher doses in the group with a progressive disorder. There may be several reasons for this. First, the size of the study sample was small. Second, in some patients care was taken not to abolish muscle tone completely, on the premise that patients may be able to use their extensor tone for transferring. Three patients (two of whom were suffering from a progressive disorder) could still make some use of their extensor tone in this way, and the dose was therefore carefully adjusted in these cases, leading to a much lower dose being given. Third, although progression of disease may play a part in the gradual escalation of drug dosage, drug tolerance is also a possible factor in patients with both progressive and non-progressive disorders. Thus the dose given not only reflects progression of disease but also associated comorbidity or complications from pump or catheter dysfunction. Finally, the functional abilities and wishes of patients must also be taken into account.

The fact that some patients suffered from certain complications more than once was not recorded as this occurred in only a small proportion of the patients and with one exception no complication occurred more than twice in a particular patient. The only exception was catheter dysfunction, which occurred five times in two patients. We only noted those complications that were directly related to the effects of baclofen and not to the underlying illness. Thus side effects from baclofen were as a rule temporary and resolved with a lowering of the dose. Although several pharmacological side effects of baclofen may occur simultaneously, it was decided to record these separately. Technical complications may include those related to the surgical procedure, dysfunction of the pump, and problems related to 
the catheter. Temporary removal of the whole pump system was necessary in two patients owing to development of meningitis in one case and persistent fever from bacteraemia in another.

The most frequent complications were related to pump or catheter dysfunction or to complications of the surgical procedure itself. Only the complications that occurred after implantation of the pump were noted. This compares well with previous studies in which complications were noted..$^{7-16} 2426$ Drug related complications and side effects were less often reported than in our study but this may reflect the fact that our patients were followed for longer, so increasing the incidence of complications. The types of drug related complications mentioned were, however, similar ${ }^{7-10}$ except for muscle weakness, which was more common in our patients.

In relation to the question of functional improvement at all health related levels (impairment, disability, and perceived health status), we were able to compare our results to some extent with three previous reports. ${ }^{4527}$ Azouvi et al ${ }^{4}$ assessed 18 patients with a follow up of three years and found, as we did, a significant decrease in tone and an increase in several FIM scores. The increase in these scores were, however, found only in paraplegic patients. Gianino et al assessed 25 patients with a mean follow up of one year. Their results were comparable with ours. In a recently published paper by Albright et al, ${ }^{27} 68$ patients participated with a follow up lasting for an average of 70 months. They only assessed spasms (their results were comparable to ours) but did not evaluate activities of daily living or quality of life.

In interpreting the results one must bear in mind the weaknesses of the current study. The following considerations are important in this respect:

First, owing to the small size of the sample, the results must be interpreted with caution, as there may be a lack of statistical power. Results with statistical significance should likewise be interpreted with caution. The fact that only 21 of the original sample of 38 patients could be evaluated gives an attrition rate of $45 \%$ which can strongly bias the results, particularly if patients who completed follow up had a better general outcome.

Second, the current assessments and measurements were undertaken by a different observer from the previous ones. ${ }^{6}$ Thus interobserver variability should be taken into account when interpreting the results.

Third, although only patients with spasticity of spinal origin were included in the study, it should be noted that several patients, particularly those with multiple sclerosis, were suffering from cerebral symptoms such as cognitive dysfunction at follow up. Cognitive abilities were also reduced in the elderly patients, who comprised a significant proportion of the sample. In answering the health related questionnaires, help from family members and caretakers was necessary and this could also have influenced the results.

\section{Conclusions}

Our study shows that the long term effect of giving intrathecal baclofen is to cause significant improvement in the level of impairment (Ashworth scale and spasm score). However, a small but significant worsening was seen at the levels of disability and the psychosocial aspects of perceived health status. Overall satisfaction was expressed by the majority of the patients. Future prospective studies of intrathecal baclofen should not be focused on impairments such as tone or spasms, because there is enough supporting evidence available. There should be a greater focus on activities of daily living such as independence or the burden of care. In respect of general quality of life, research should be focused on the patients' expectation versus experience as a measure of satisfaction with intrathecal baclofen.

\section{Authors' affiliations}

A Zahavi, J H B Geertzen, J S Rietman, Department of Rehabilitation, University Groningen, Netherlands

B Middel, Northern Centre for Health Care Research, University

Groningen

M Staal, Department of Neurosurgery, University Groningen

Competing interests: none declared

\section{REFERENCES}

1 Penn RD, Kroin JS. Continuous intrathecal baclofen for severe spasticity. Lancet 1985;ii: 125-7.

2 Müller H, Zierski J, Dralle D. Pharmacokinetics of intrathecal baclofen. In: Müller H, Zierski J, Penn RD, eds. Local-spinal therapy of spasticity. Berlin: Springer Verlag, 1988:223-6.

3 Aisen ML, Dietz MA, Rossi P. Clinical and pharmacokinetic aspects of high dose oral baclofen therapy. J Am Paraplegia Soc 1992;15:211-16.

4 Azouvi P, Mane M, Thiebaut JB, et al. Intrathecal baclofen administration for control of severe spinal spasticity: functional improvement and long-term follow-up. Arch Phys Med Rehabil 1996;77:35-9.

5 Gianino JM, York MM, Paice JA, et al. Quality of life: effect of reduced spasticity from intrathecal baclofen. J Neurosci Nurs 1998;30:47-54.

6 Middel B, Kuipers-Upmeijer H, Bouma J, et al. Effect of intrathecal baclofen delivered by an implanted programmable pump on health related quality of life in patients with severe spasticity. I Neurol Neurosurg Psychiatry 1997;63:204-9.

7 Coffey JR, Cahill D, Steers W, et al. Intrathecal baclofen for intractable spasticity of spinal origin: results of a long-term multicenter study. J Neurosurg
$1993 ; 78: 226-32$.

8 Abel NA, Smith RA. Intrathecal baclofen for treatment of intractable spinal spasticity. Arch Phys Med Rehabil 1994;75:54-8.

9 Penn RD. Intrathecal baclofen for spasticity of spinal origin: seven years of experience. J Neurosurg 1992;77:236-40.

10 Ordia JI, Fischer E, Adamski E, et al. Chronic intrathecal delivery of baclofen by a programmable pump for the treatment of severe spasticity. I Neurosurg 1996;85:452-7.

11 Mertens P, Parise M, Garcia-Larrea L, et al. Long-term clinical, electrophysiological and urodynamic effects of chronic intrathecal baclofen infusion for treatment of spinal spasticity. Acta Neurochir Suppl Wien 1995;64:17-25.

12 Patterson V, Watt M, Byrnes D, et al. Management of severe spasticity with intrathecal baclofen delivered by a manually operated pump. J Neurol Neurosurg Psychiatry 1994;57:582-5.

13 Gardner B, Jamous A, Teddy P, et al. Intrathecal baclofen: a multicentre clinical comparison of the Medtronics Programmable, Cordis Secor and Constant Infusion Infusaid drug delivery systems. Paraplegia 1995;33:551-4.

14 Penn RD. Intrathecal baclofen for severe spasticity. Ann NY Acad Sci 1988;531:157-66.

15 Penn RD, Savoy SM, Corcos D, et al. Intrathecal baclofen for severe spinal spasticity. N Engl J Med 1989;320:1517-21.

16 Nance $P$, Schryvers $O$, Schmidt B, et al. Intrathecal baclofen therapy for adults with spinal spasticity: therapeutic efficacy and effect on hospital admissions. Can J Neurol Sci 1995;22:22-9.

17 Saltuari L, Kronenberg M, Marosi MJ, et al. Indication, efficiency and complications of intrathecal pump supported baclofen treatment in spinal spasticity. Acta Neurol Napol 1992;14:187-94.

18 Ashworth B. Preliminary trial of carisoprodol in multiple sclerosis. Practitioner 1964;192:540-2.

19 Kurtzke JF. Rating neurologic impairment in multiple sclerosis: an expanded disability status scale (EDSS). Neurology 1983;33:1444-52.

20 La Rocca N. Field testing of a minimal record of disability in multiple sclerosis: the United States and Canada. Acta Neurol Scand 1984;70(suppl 101): 126-38.

21 Bergner M, Bobbit RA, Carter WB, et al. The sickness impact profile: development and final revision of a health status measure. Med Care $1981 ; 19: 787-805$.

22 Luteyn F, Hamel LF, Bouman TK. Hopkins symptom checklist (manual). Lisse: Swets and Zeitlinger, 1984.

23 Cohen J. Statistical power analysis for the behavioural sciences. New York: Academic Press, 1977.

24 Penn RD, Kroin JS. Long-term intrathecal baclofen infusion for treatment of spasticity. J Neurosurg 1987;66:181-5.

25 Parke B, Penn RD, Savoy SM, et al. Functional outcome of intrathecal baclofen. Arch Phys Med Rehabil 1989;70:30-2

26 Meythaler JM, Steers WD, Tuel SM, et al. Continuous intrathecal baclofen in spinal cord spasticity. A prospective study. Am J Phys Med Rehabil 1992;71:321-7.

27 Allbright AL, Gilmartin R, Swift D, et al. Long-term intrathecal baclofen therapy for severe spasticity of cerebellar origin. J Neurosurg 2003;98:291-5. 